Proceeding of the Public Health and Well-being Conference, Vol. 1, 2021, pp. 80-91

Copyright (C) 2021 iConferences

ISSN 2659-2096

DOI: https://doi.org/10.32789/publichealth.2021.1007

\title{
Andragogy in Continuous Medical Education: The Medical Teachers' Perception on Continuous Medical Education
}

Bawani Nesamany ${ }^{1}$, Joel See Pih Liang ${ }^{1}$, Mike Chan ${ }^{1}$, Michelle Wong ${ }^{1}$, Dmytro $\mathrm{Klokol}^{1}$

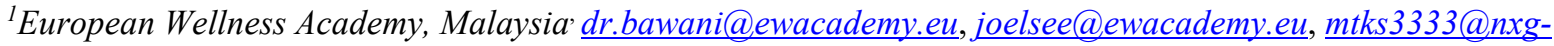
global.com,wbf6666@nxg-global.com,dr.dmytro@sbi-europe.com 


\title{
ANDRAGOGY IN CONTINUOUS MEDICAL EDUCATION: THE MEDICAL TEACHERS' PERCEPTION ON CONTINUOUS MEDICAL EDUCATION
}

\begin{abstract}
In order to impact Continuous Medical Education (CME) change, perception of medical educators, better delivery, and elements of inclusivity to existing programs are essential with the acceptance that is a postgraduate phenomenon. To make that change possible, physician educators need to be aware of the ever-changing healthcare revolving around inevitable patient needs. A study was conducted to investigate the key areas affecting CME performance at a private tertiary medical education. Despite the convenient sampling and limitations, the study confirmed that medical educators need active intervention and should be empowered with perception alignment. The active intervention of CME delivery to meet the intended aftermath can only result in a whirlpool effect when all layers of contributors to CME development and application are involved in the measures. This emphasis needs educators to be on board with what and where CME is, where and how it shall propagate a high-quality medical education system. This is vital to reassure the unrelenting delivery of outcome achieving medicine for all.
\end{abstract}

Keywords: Medical education, Medical Universities, Medical Lecturers

\section{Introduction}

Continuing Medical Education (CME) is an active life-long process of every physician officiating in undergraduate years and extends to their clinical years. It is a mandatory tool of practice that is believed to enhance the knowledge of physicians in order to maintain active licensure and Human Resources Management Requisition and Personal Development. According to the American Medical Association (AMA) and the Accreditation Council for Continuing Medical Education (ACCME), CME comprises of educational activities which aim to maintain, develop and increase the knowledge, skills, and professional performance that physicians and allied health professionals use to provide services for patients, the public or the profession. Even though CME is accepted as a pertinent part of professional growth in the medical sector, the CME itself needs vigorous review and re-evaluation. Besides re-evaluation and reshuffling of the system, the physicians should recognize and familiarize themselves with the content of CME, which assists them in carrying out their professional responsibilities more effectively and efficiently.

\section{The CME Journey}

Physicians are the building blocks of the healthcare system. The dedication and sacrifice for life-long learning are crucial for self-directed professional development. This research was done with the objective to diligently study the medical educators'/physicians' perspective on the existing CME effectivity. This study serves as a tool to gauge the gaps and challenges within the current CME system. This study presents the basic quantitative analysis of current medical educators' responses in the context of continuing professional education in the medical field. The research outcome has also shown that the CME system has remained stagnant over the years and demands vigorous review and change to better the system and society as a whole. Hence, there are models and recommendations 
suggested as solution-providers, which can be abided, to measure the effectiveness and efficiency of the revised system.

The arrival and explosive growth of technologies has resulted in the evolution of medical practices and further bifurcation of medicine into other branches, namely Regenerative Medicine, Complementary Medicine, Integrative Medicine. CME is intertwined and closely related to all layers of medical professionalism. The dysfunction of one layer will directly impact the consecutive layers and result in stagnation and even failure of the system as a whole. Therefore, it is necessary to keep the synergism between CME and the medical health care sector intact for medicine and selfprofessional development. However, it is alarming that the consumers of CME, the practicing physicians-medical educator lack clear demarcation on what constitutes and how it could drive lifelong learning. Besides dwelling in a poorly understood concept, the CME providers also somewhat have contributed to the overall stagnation of this system. The diagram below depicts the current system of CME.

\section{The Medical Educators}

The organizational environment and climate experienced by staff are strongly correlated to the educational environment and climate received by the students. It is because the curriculum is operationalized or manifested towards students and medical educators. Hence, we need to emphasize the organizational environment and climate circulated around medical educators, their perception, their influence on the curriculum, instruction, and the learner with the focal center of interest on students, which nudges toward achieving quality patient care. Internally, if this multifaceted loop is not peeled arduously around the medical educator, training them, empowering them, rationalizing and influencing them progressively toward scaffolding the learners in becoming active continuous medical education purposefully, circumstantial and pharmaceutical stake-holder influence will lead by default, subtly. This does not deny the lead which has been in place for over a century.

Medical schools and all other faculties and academic departments of universities worldwide have recently been compelled to account for the reliability of the performance outcomes of the educational enterprise to government, other monetarily, or influential stakeholders. They have been exposed to, and some may say, "threatened" by having evaluation and progress monitoring through an audit and performance standards. Conversely, there might be, or should be, no valid explanation why the significance of both quality assurance (QA) and continuous quality improvement and innovation (CQII) and the clear partnership between CQII and QA would not be recognized by all stakeholders of the institution, including benefactors, administrators, staff and students.

It is expected that this discourse of assistance and facilitation would lead to some rationalization and strong clarification of contact between all stakeholders, which, it is assumed, will only help boost the value and efficiency of the role of all members in the medical education sector.

Perhaps even more unique is the perception in this curriculum; the medical education system is also an experience for medical staff, and that anything that occurred to them in their professional lives, as a key stakeholder and as a paramount individual in the institution or organization. Nevertheless, there 
seems to be a propensity to miss some of the complexity, finesse, and variety of the tapestry of medical education knowledge, which is important in the necessity and significant problems for curriculum design systems, templates, diagrams, and logistics.

The urge for a new medical education environment is a necessity stated by the American Association of Medical Colleges (AAMC) due to the unprecedented changes in educational and organizational environments. Such call for change, which has been around for decades and will continue to exist, intrigued to gauge the perception of medical educators' perception of continuous medical education in this paper.

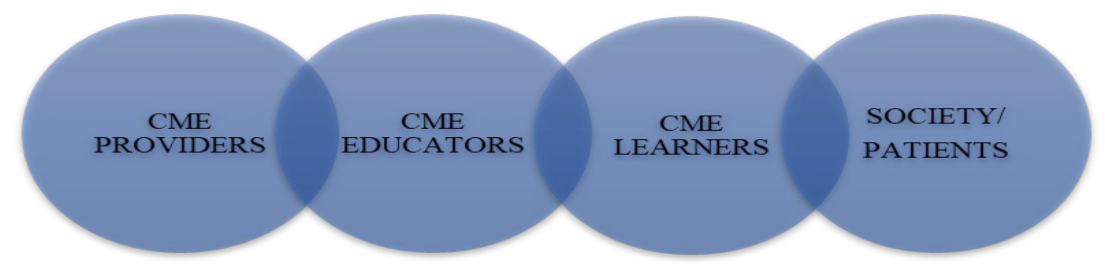

Figure 1 The CME Factors

\section{Transformation in Current Medical Education}

The four objectives for aiming the revolutionary programmatic strategies in medical education may be accomplished by standardizing learning outcomes and individualizing the learning process; incorporating knowledge and clinical perspectives, tasks, and responsibilities; establishing habits of inquiry and improvement; specifically, address professional formation.

One of the proposed ideas of transformation that needs to be implemented is that learners should not waste their time unproductively by repeating clinical tasks until they have perfected the skills appropriate to their level, as this discourages medical students and residents from cultivating and exploring their medical interest and non-clinical responsibilities. Teaching methods must highlight that competence requires a minimum standard; it is the degree of excellence that must be reached by all aspiring doctors about the center for effective interaction and institutionalization for learners. The core pedagogy of medical education seeks to enable learners to acquire the confidence and expertise needed to educate themselves, motivated in clinical settings by their clinical encounters, observations, and interactions. Students and residents need good, committed relationships with faculty members who can stipulate challenge, encouragement, strong role models, and guidance opportunities during their medical education.

Medical education also wants to guarantee that learners attain predetermined standards of competence with respect to knowledge and performance by integrated and cumulative assessment. Hence, standardizing learning outcomes and individualizing learning processes is recommended to revamp the programmatic medical education. Besides that, learners' knowledge and clinical experience, roles, and responsibilities need to be consolidated, and senses of inquiry and improvement must be developed. Also, professional identity formation needs to be acknowledged explicitly to support the dual relationship. 
Overall, these programmatic interventions need to be carried out to illustrate how the objective must be achieved by curriculum, pedagogy, and assessment. However, there are always difficulties in incorporating these methods into current medical education.

The effectiveness of the current CME has been obliged to many challenges due to multiple factors, resulting in an overall misbalance of the system. The diagram below will be able to depict the current misbalance in the CME system:

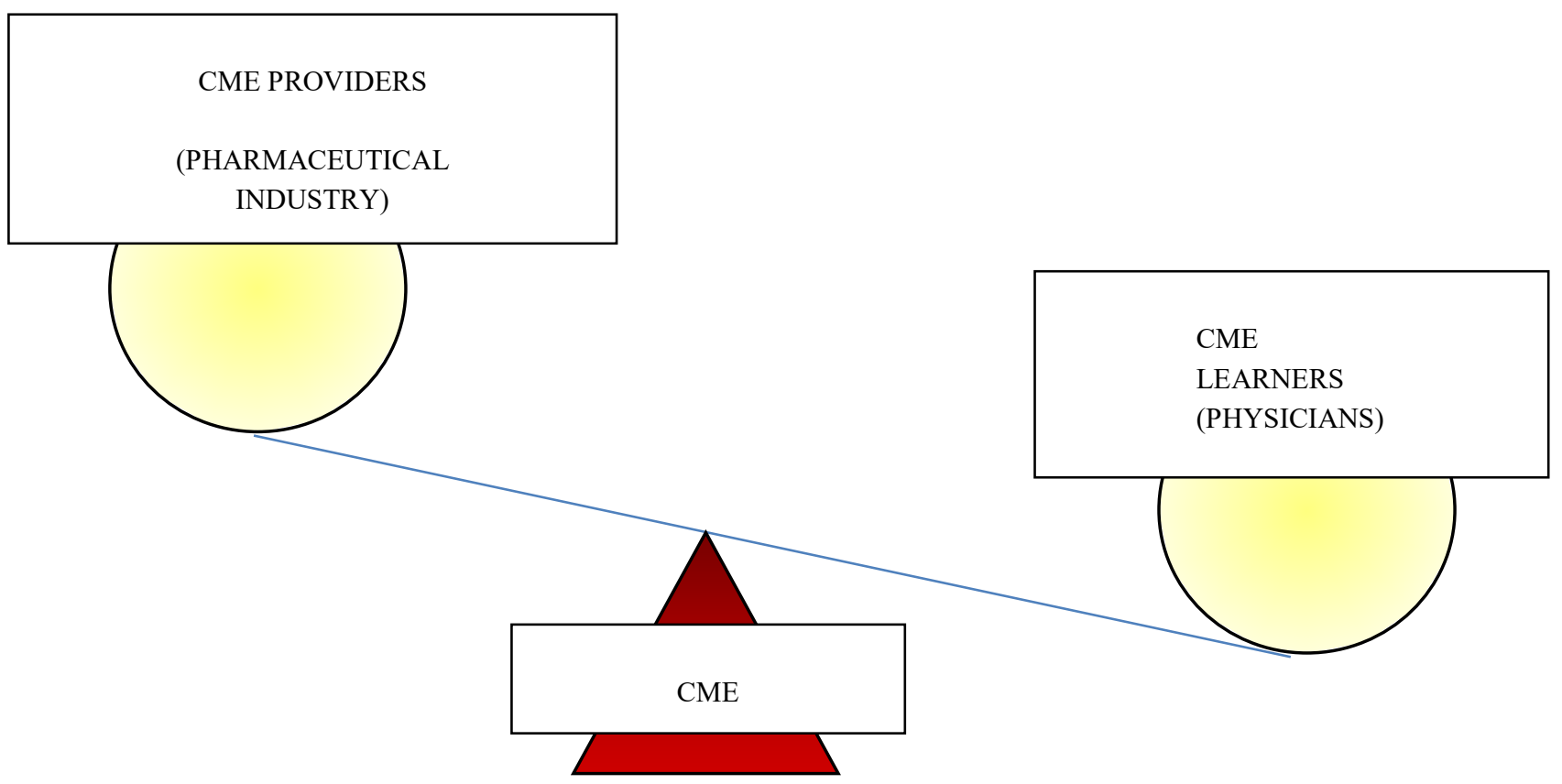

Figure 2 The misbalance in the system of CME demands review, re-evaluation, and change of the system for today's and tomorrow's needs.

\section{Methodology}

This survey was conducted in a local private medical university that offers various undergraduate, postgraduate, and doctorate studies on medical sciences, dental sciences, and biotechnological studies. This university is ranked among the top 10 medical sciences universities in South East Asia. This survey was conducted during a 3-day International Scientific Conference which was held in their campus, with consent. This survey of questionnaires was directed to a group of 100 respondents of only medical teachers (educators) from the Faculty of Medicine. However, only 79 questionnaires are valid, while the remaining set of questionnaires are invalid for data analysis due to the incompletion of the questionnaire. The questionnaire consists of 10 items that gather responses with a Likert Scale of five. 
Convenience sampling was the by-default process that was made available as this is the institute to which we had access and consented to the case study. A survey questionnaire with 10 items divided into 3 categories was developed by the author and co-authors. Items 1, 6, 7, and 8 intend to verify the medical teacher's awareness of CME. Items 2, 3, and 9 intend to verify the medical teachers' perception of the CME's inclusiveness. Items 3, 4, and 10 intend to verify the medical teachers' perception of CME's quality

The predetermined, purposefully filtered population are the medical educators due to their significant role in educating the future generation of young physicians; hence this survey was conducted with an intent to identify the physicians '/medical educators' perspective on the effectiveness of the existing CME. The recognition of the effectiveness of CME by the medical educators of pre-dominance in foreign nationality has given rise to efforts to better understand the challenges and deficiency of the CME system. The sample type and size limitations and collation of data for a better estimate of outcomes in small but specific populations prevent the data from qualifying a generalizable analysis.

\section{Results}

The data obtained from the sample have been summed and represented in the basic histograms below, in the order of the item in the survey sheet.

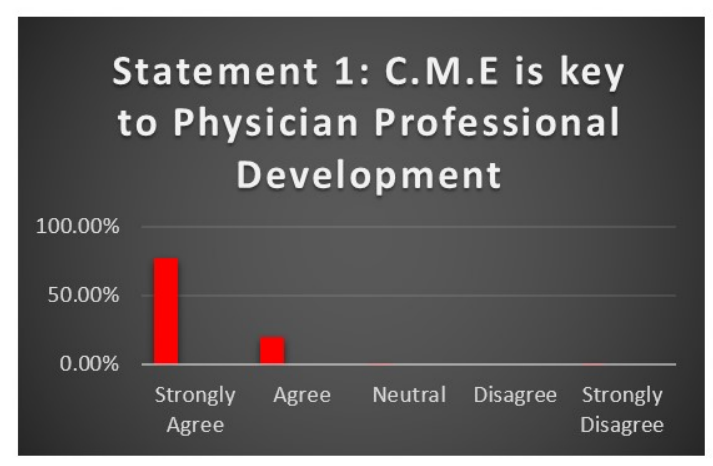

Statement 1 concludes that the majority of respondents, who consist of 61 respondents $(\mathbf{7 7 . 2 \%}$ ) from the total of 79 respondents strongly agreed to the fact that the Continuous Medical Education is key to Physician Professional Development.

However, 1 respondent $(\mathbf{1 . 3 \%})$ strongly disagreed to the statement above. 16 respondents, $\mathbf{( 2 0 . 3 \% )}$ ) agreed to the statement above.

0 respondent $(0 \%)$, disagreed to the statement above. While 1 respondent $(\mathbf{1 . 3 \%})$ was neutral to this statement.

Item 1

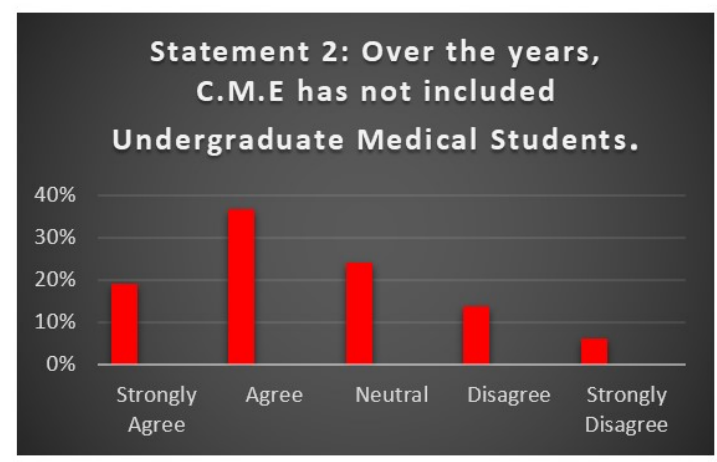

Statement 2 concludes that the majority of respondents, who consist of 15 respondents (19\%) from the total of 79 respondents strongly agreed to the fact that over the years CME has not included Undergraduate Medical Students. However, 5 respondents $(6.3 \%)$ strongly disagreed to the statement above.

29 respondents, $(36.7 \%)$ agreed to the statement above. Only 11 respondents $(\mathbf{1 3 . 9 \%})$, disagreed to the statement above.

19 respondents $(\mathbf{2 4 . 1} \%)$ were neutral to the statement above.

\section{Item 2}




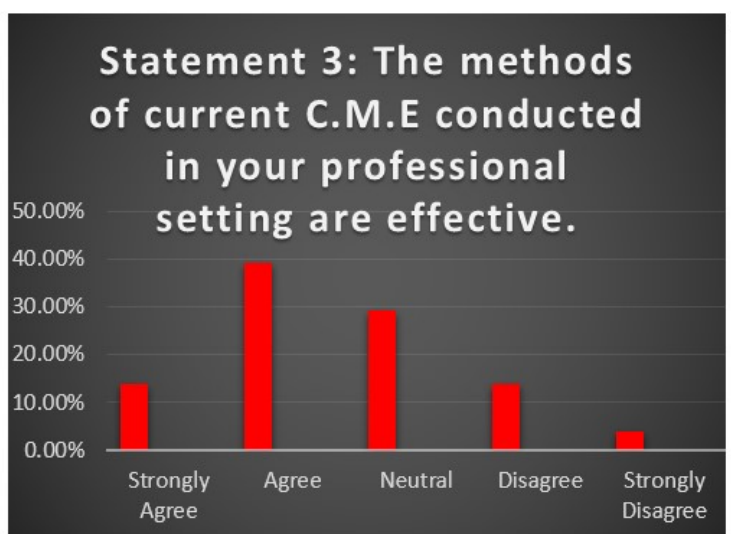

Statement 3 concludes that the majority of respondents, who consist of $\mathbf{3 1}$ respondents $\mathbf{( 3 9 . 2 \% )}$ ) from the total of 79 respondents agreed to the fact that over the methods of current CME conducted in your professional setting are effective.

However, 3 respondents $\mathbf{( 3 . 8 \% )}$ ) strongly disagreed to the statement above.

11 respondents, $(\mathbf{1 3 . 9 \% )}$ ) strongly agreed to the statement above.

11 respondents $(\mathbf{1 3 . 9 \%})$, disagreed to the statement above. 23 respondents $(\mathbf{2 9 . 1 \% )})$ were neutral to the statement above.

\section{Item 3}

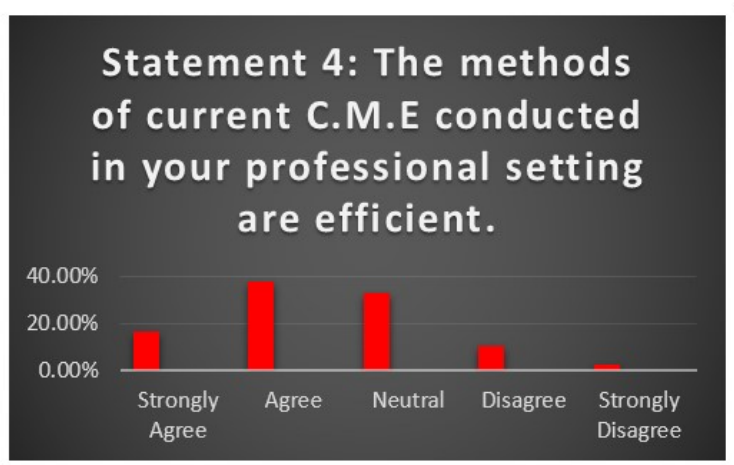

Statement 4 concludes that the majority of respondents, who consist of $\mathbf{3 0}$ respondents (38\%) from the total of 79 respondents agreed to the fact that over the methods of current $\mathrm{CME}$ conducted in your professional setting are efficient.

However, 2 respondents $\mathbf{( 2 . 5 \% )}$ strongly disagreed to the statement above.

13 respondents, $(\mathbf{1 6 . 5 \% )}$ ) who strongly agreed to the statement above while 8 respondents $(\mathbf{1 0 . 1 \%})$, disagreed to the statement above.

26 respondents $(\mathbf{3 2 . 9 \%})$ were neutral to the statement above.

\section{Item 4}

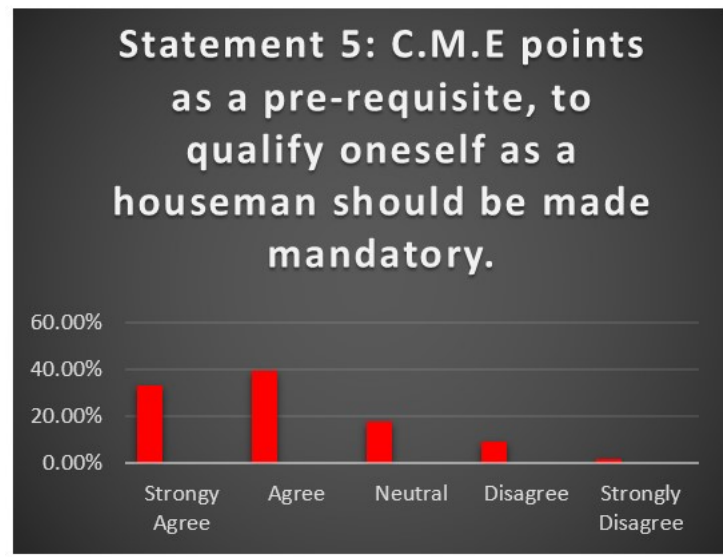

Statement 5 concludes that the majority of respondents, who consist of $\mathbf{3 1}$ respondents $\mathbf{( 3 9 . 2 \% )}$ ) from the total of 79 respondents agreed to the fact that $\mathrm{CME}$ points as a prerequisite, to qualify oneself as a houseman should be made mandatory.

However, 1 respondent $(\mathbf{1 . 3 \% )}$ strongly disagreed to the statement above.

26 respondents, $(\mathbf{3 2 . 9 \% )}$ ) strongly agreed to the statement above.

Only 7 respondents $(8.9 \%)$, disagreed to the statement above.

14 respondents $(\mathbf{1 7 . 7 \%})$ were neutral to the statement above.

\section{Item 5}




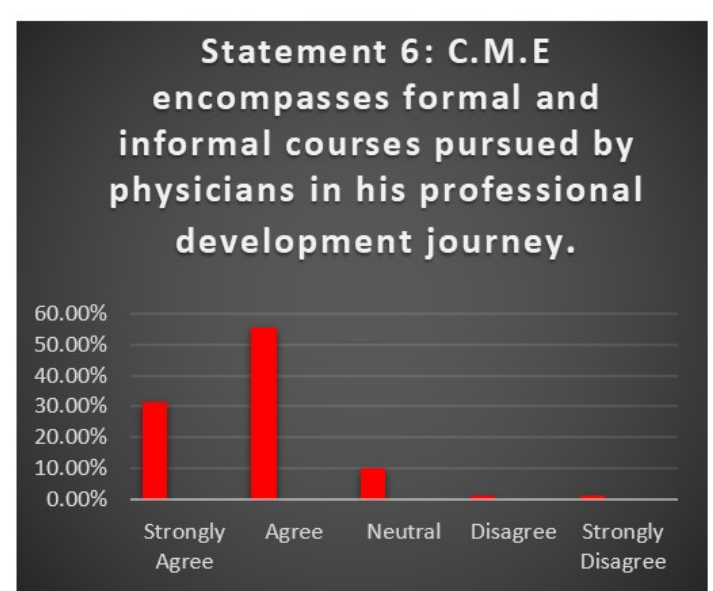

Item 6

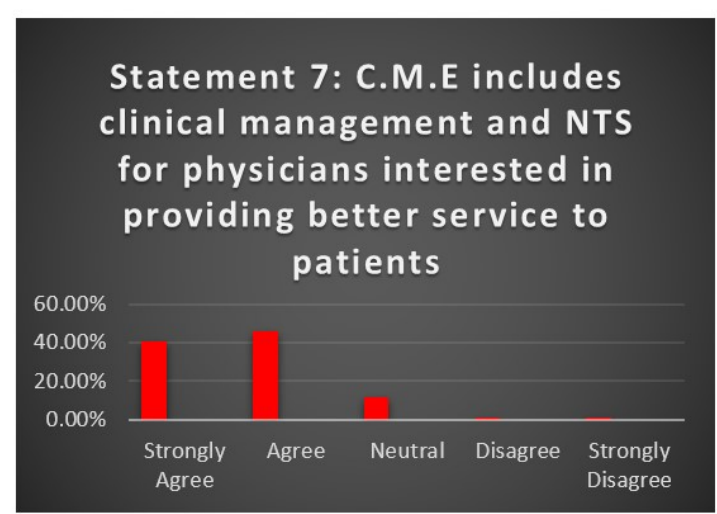

Item 7

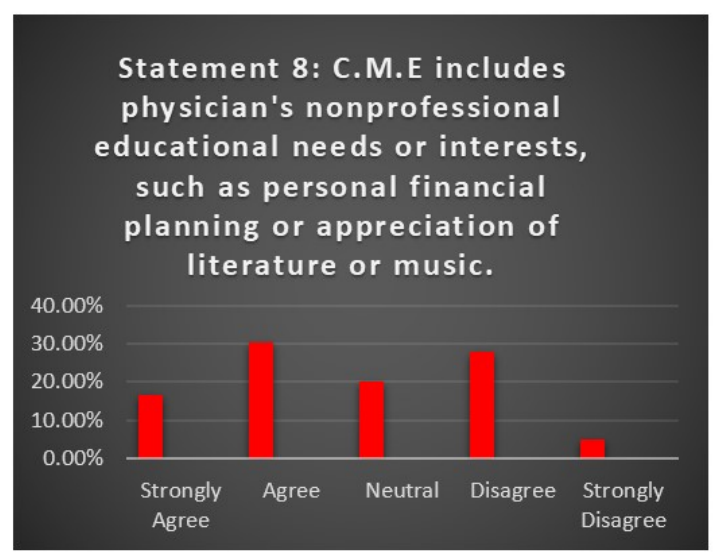

Statement 8 concludes that the majority of respondents, who consist of $\mathbf{1 3}$ respondents $(\mathbf{1 6 . 5 \%})$ from the total of 79 respondents strongly agreed to the fact that $\mathrm{CME}$ includes physicians' nonprofessional education needs or interests, such as personal financial planning or appreciation of literature or music.

However, 4 respondents $(\mathbf{5 . 1 \% )}$ ) strongly disagreed to the statement above.

24 respondents, $(\mathbf{3 0 . 4 \% )}$ ) agreed to the statement above. 22 respondents $(\mathbf{2 7 . 8 \%})$, disagreed to the statement above. Only 16 respondents, $(20.3 \%)$ were neutral to the statement above.

10 respondents $(\mathbf{2 1 \%})$ were neutral to the statement above.

\section{Item 8}




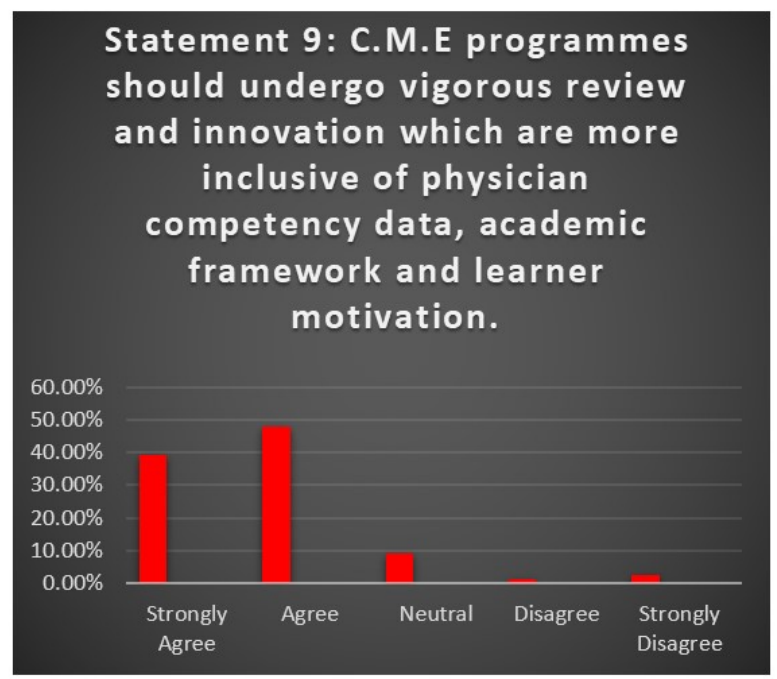

Statement 9 concludes that the majority of respondents, who consist of 38 respondents $(\mathbf{4 8 . 1 \%})$ from the total of 79 respondents agreed to the fact that $\mathbf{C M E}$ programs should undergo vigorous review and innovation which are more inclusive of physician competency data, academic framework and learner motivation.

However, 2 respondents (2.5\%) strongly disagreed to the statement above.

31 respondents, $(39.2 \%)$ strongly agreed to the statement above. Only 1 respondent, $(1.3 \%)$, disagreed to the statement above.

7 respondents, $(8.9 \%)$ were neutral to the statement above.

\section{Item 9}

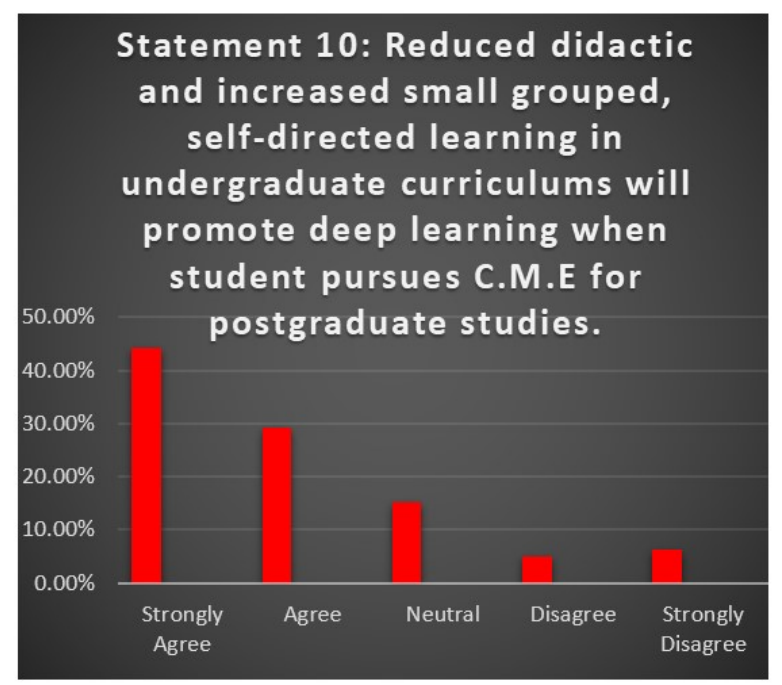

Statement 10 concludes that the majority of respondents, who consist of 35 respondents (44.3\%) from the total of 79 respondents strongly agreed to the fact that reduced didactic and increased small grouped, self-directed learning in undergraduate curriculums will promote deep learning when student pursues $\mathrm{CME}$ for postgraduate studies. However, 5 respondents $(\mathbf{6 . 3 \%})$ strongly disagreed to the statement above.

23 respondents, $(\mathbf{2 9 . 1 \%})$ agreed to the statement above. Only 4 respondents, $(5.1 \%)$, disagreed to the statement above.

However, 12 respondents, $(\mathbf{1 5 . 2 \% )}$ ) were neutral to the statement above.

\section{Item 10}

\section{Discussion}

The awareness that Continuous Medical Education is key to a Physician's Professional Development among the respondent medical educators gives a benign reassurance, although this data is not generalizable. The acknowledgment that over the years, CME has not involved the undergraduates is clear with a majority of $55.7 \%$, although it raises a concern for the $30.2 \%$ who disagreed.

Azzam (2014, p348) asked, 'Yet even while this 'seismic shift' in education is occurring for students from birth through their undergraduate training, it is not yet as clear how that might translate to the world of medical students, let alone graduate medical education. Will these forces change a field often cited as one of lifelong learning?' 
Item 2 links to item 5, whereby the need for a houseman to have CME points to be given housemanship was supported heavily with a $72.10 \%$. The limitation of this survey items' scale became visible at item 2. The survey did not undergo a pilot study due to the narrow deadlines between item preparation and data collection. The Likert scale assigned to the survey perhaps would have best fit four and not five scale. The 5 scale with the 3-Neutral left a vast majority of responses lost to neutral. This made the data obtained to determine the awareness, inclusivity, and quality of Continuous Medical Education perception of the medical educators to be docilely above average. Items 3 and 4 are to gauge the perception of the medical educator on the quality of CME, along with item 10, where a contradiction was implying change needed for CME, especially for postgraduate. The predicted link was seen in response to items 3 and 4 to that of item 10. As for the response to items 3 and 4 is seen, response to item 10, arguably is concluded that those who responded neutral to items 3 and 4, which relays the effectiveness and efficacy of $\mathrm{CME}$, took to agree or strongly agree that CME needs three key changes to promote deep learning among students as they pursue postgraduate studies.

Azzam (2014, p353) also states 'As learning teams become less hierarchical, I'd propose reciprocal 'educator development plans' that are bravely shared with learners as well. This would acknowledge that the teacher does not have all the answers and is also growing as a professional while simultaneously highlighting the mutual commitment to increasing knowledge and understanding of both educators and learners alike. After all, learners in the developed world already have access to more information at all times at their fingertips than exists in all their faculty members' collective brains. Therefore, the role of medical school staff is no longer medical knowledge transfer, but soon to be (already?) other key functions, such as assisting with their learners' professional identity formations, role-modeling lifelong learning, and sharing how a professional sifts through the mountain of information to determine what is appropriately high quality and sufficiently reliable to use in the care of one's patients.'

However, the drop in neutral respondents to item 10 is more than half. The respondents to the neutral scale in items 3 and 4 are $29.1 \%$ and $32.9 \%$. As conveyed, the response for item 10, the agreeing scale respondents whooped at a $73.4 \%$ with only 12 respondents to neutral scale; the disagree scale respondents did not drop below half. Items 7 and 8 are meant to contradict one another with an estimate to capture clarity in CME understanding. Item 8 had 36 respondents, almost $50 \%$ agreeing that CME includes personal financial planning, art, and music as non-professional educational needs of the physician. This summed the survey as indicating the need to peel, comb, analyze interlink and run more data collection in this area to gauge medical educators on their perception of CME.

\section{Limitation}

As stipulated in the discussion, the key vices are the lack of larger pilot testing of the survey items, convenience sampling, and lack of time to conduct a qualitative data collection with the same population set as their input is very valuable.

\section{Recommendation}

Given the opportunity for the same population to be made respondents, the peeled multilayer items specifically exploring CME views and awareness of medical educators along qualitative data collection to gather input on patterns assumed to exist between item responses. 


\section{Conclusion}

The rudimentary connection that could be established from the response gathered from the medical educators (teachers), and review of information across available resources makes it clear that the technology speed of development in facilitating education will not spare medical education, especially Continuous Medical Education. However, there is no substantial claim that could confirm the possible replacement of medical educators with the arrival of technology. Furthermore, the need for medical educators to play a mentor role, navigating the learners' process of knowledge acquisition and experience in the application of knowledge to impact patient care, will continue to prevail. As such, the clear comprehension of a medical educator (teacher) on what Continuous Medical Education is, the current efficiency and efficacy, curriculum design and instruction motivation, and evolution of CME intended outcome. The key is to be able to bridge both the self's and ignite the learner's lifelong learning compass while actively, purposefully being abreast with the belief that one (the medical educator) is pertinent in instilling the clear plan-development ability (skill) in the learner. This should plant the urge (seed) for the lifelong continuous pursuit of medical education, purposefully, cohesively, and not accidentally or by council obligation.

\section{References}

Azzam, A., 2013. As technology and generations in medical education change, what remains is the intersection between educator, learners, assessment and context. International Review of Psychiatry, 25(3), pp.347-356.

Boyd, V.A., Whitehead, C.R., Thille, P., Ginsburg, S., Brydges, R. and Kuper, A., 2018. Competency based medical education: the discourse of infallibility. Medical Education, 52(1), pp.45-57.

Cantillon, P. and Jones, R., 1999. Does continuing medical education in general practice make a difference? $B M J, 318$ (7193), pp.1276-1279.

Caverzagie, K.J., Nousiainen, M.T., Ferguson, P.C., Ten Cate, O., Ross, S., Harris, K.A., Busari, J., Bould, M.D., Bouchard, J., Iobst, W.F. and Carraccio, C., 2017. Overarching challenges to the implementation of competency-based medical education. Medical Teacher, 39(6), pp.588-593.

Davis, D., O'Brien, M.A.T., Freemantle, N., Wolf, F.M., Mazmanian, P. and Taylor-Vaisey, A., 1999. Impact of formal continuing medical education: do conferences, workshops, rounds, and other traditional continuing education activities change physician behavior or health care outcomes? Jama, 282(9), pp.867-874.

Finnerty, E.P., Chauvin, S., Bonaminio, G., Andrews, M., Carroll, R.G. and Pangaro, L.N., 2010. Flexnerrevisited: the role and value of the basic sciences in medical education. Academie Medicine, 85(2), pp.349-355.

Genn, J.M., 2001. AMEE Medical Education Guide No. 23 (Part 1): Curriculum, environment, climate, quality and change in medical education-a unifying perspective. Medical Teacher, 23(4), pp.337-344

Genn, J.M., 2001. AMEE Medical Education Guide No. 23 (Part 2): Curriculum, environment, climate, quality and change in medical education-a unifying perspective. Medical Teacher, 23(5), pp.445-454.

Hatem, C.J., Searle, N.S., Gunderman, R., Krane, N.K., Perkowski, L., Schutze, G.E. and Steinert, Y., 2011. The educational attributes and responsibilities of effective medical educators. Academic Medicine, 86(4), pp.474-480.

Holm, H.A., 1998. Quality issues in continuing medical education. BMJ, 316(7131), pp.621-624.

Holmboe, E.S., 2015. Realizing the promise of competency-based medical education. Academic Medicine, 90(4), pp.411-413. 
Holmboe, E.S., Sherbino, J., Englander, R., Snell, L., Frank, J.R. and ICBME Collaborators, 2017. A call to action: the controversy of and rationale for competency-based medical education. Medical Teacher, 39(6), pp.574-581.

Iobst, W.F., Sherbino, J., Cate, O.T., Richardson, D.L., Dath, D., Swing, S.R., Harris, P., Mungroo, R., Holmboe, E.S., Frank, J.R. and International CBME Collaborators, 2010. Competency-based medical education in postgraduate medical education. Medical Teacher, 32(8), pp.651-656.

Jones, R., Higgs, R., De Angelis, C. and Prideaux, D., 2001. Changing face of medical curricula. The Lancet, 357(9257), pp.699-703.

Lewis, K.O., Cidon, M.J., Seto, T.L., Chen, H. and Mahan, J.D., 2014. Leveraging e-learning in medical education. Current Problems in Pediatric and Adolescent Health Care, 44(6), pp.150-163.

Mazmanian, P.E. and Davis, D.A., 2002. Continuing medical education and the physician as a learner: guide to the evidence. Jama, 288(9), pp.1057-1060.

Murdoch-Eaton, D. and Whittle, S., 2012. Generic skills in medical education: developing the tools for successful lifelong learning. Medical education, 46(1), pp.120-128.Seifer, S.D., 1998. Recent and emerging trends in undergraduate medical education. Curricular responses to a rapidly changing health care system. Western Journal of Medicine, 168(5), p.400.

Spencer, J.A. and Jordan, R.K., 1999. Learner centred approaches in medical education. BMJ, 318(7193), pp.1280-1283.

Touchie, C. and ten Cate, O., 2015. The promise, perils, problems and progress of competency-based medical education. Medical Education, 50(1), pp.93-100. 